\title{
Interactive comment on "Response of winter fine particulate matter concentrations to emission and meteorology changes in North China” by M. Gao et al.
}

\section{Anonymous Referee \#1}

Received and published: 2 August 2016

This paper investigated the responses of PM2.5 concentrations to changes in emissions (incl. SO2, NOx, NH3, BC and $\mathrm{OC}$ ) and meteorology (incl. $\mathrm{T}, \mathrm{RH}$ and wind speed) for a severe haze season in North China. Multiple sensitivity cases along with the baseline scenario in January 2010 were conducted with an online coupled meteorological and chemical transport model (i.e., WRF-Chem). The result suggests that dramatic changes in emissions are main cause of the increasing haze event in north China, and the winter PM2.5 is largely contributed by $\mathrm{SO} 2$ and NH3 emissions, as well as wind speed and aerosol feedbacks. The study is an important and very worthwhile exercise. Publication of the manuscript is recommended with minor revisions as suggested. 
Detailed WRF configuration and emission processing is necessary. For example, there is little information regarding the WRF parameterization, nudging, how the feedback was set up. It is also necessary to provide basic details of model domain, particularly for the vertical profile. How the emissions were located vertically across the PBL? How the emissions and meteorological variables were adjusted in the sensitivity runs at different vertical heights?

Besides, discussion about the limitation of this study is necessary, such as lack of proper SOA simulation, no consideration of VOC and primary PM emission other than $\mathrm{BC} / \mathrm{OC}$. The simulation period was just one month in winter, results might be different in other seasons. The 13 simulation cases need to be discussed in the text, although they've been well summarized in Table 1. I would suggest to elaborate them in the method section.

Specific Comments:

Page 5 Line 9-10, some of the previous studies also used online coupled model, e.g., Wang et al ERL 2014, please clarify it.

Page 7 Line 16, did those changes apply to all vertical layers or just the ground? Is there any evidence to support those numbers?

Page 9 Line 12, elevated sources such as power plants and industry boilers are even more important than near-ground sources in China.

Page 10 Line 5, there is no data about natural dust provided in Table 2.

Page 10 Line 16-17, does that mean SOA is not important in China? It seems problematic.

Page 12 Line 10-11, please elaborate the reason.

Page 12 Line 11-12, NH3NO3 should be NH4NO3. The sentence is confusing. Does 
that mean north China exhibits NH3 poor condition in winter?

Page 15 Line 20-21, please elaborate the reason, e.g., changes in T vertical profile?

Page 16 Line 8-9, a little confusing...but PM shows clear increases in Beijing.

Page 19 Line 20, the sensitivity represents the response per unit change, I suppose here it means the response to total changes. Please clarity it.

Interactive

comment

Page 20 Line 10, how was the prediction conducted?

Figure 1, I suggest to present total emissions in column rather than at surface only.

Figure 2, is it based on the meteorology in Jan 2010 ?

Figure 4, negative scale is too large to show any difference, please consider to modify it.

Interactive comment on Atmos. Chem. Phys. Discuss., doi:10.5194/acp-2016-429, 2016. 